\title{
Burn Wounds: Infection and Healing
}

David J. Smith, Jr., MD, Amn Arbor, Michigan, Phillip D. Thomson, PhD, St. Louis, Missouri, Warren L. Garner, MD, Jorge L. Rodriguez, MD, Ann Arbor, Michigan

Early wound closure is the ultimate goal of burn care. While excisional therapy is necessary in the treatment of both large, full-thickness and deep, partial skin-thickness burns, the majority of burns are superficial partial skin-thickness injuries requiring a different clinical approach. In superficial wounds, cosmetic and functional restoration in conjunction with relief from pain and prevention of infection is as important as rapid wound closure. The moist wound healing associated with hydrocolloid dressings may provide an alternative treatment modality for certain partial-thickness injuries. In comparable wounds, these dressings produce good functional and cosmetic results, rapid reepithelialization, and improved patient comfort.
From the Department of Surgery, University of Michigan Medical Center, Ann Arbor, Michigan (D.J.S., W.L.G., J.L.R.); the Technology Planning Division, Mallinckrodt Medical, Inc., St. Louis, Missouri (P.D.T.).

David J. Smith, Jr., MD, and Phillip D. Thomson, PhD, acknowledge support in part for research and travel from ConvaTec.

Requests for reprints should be addressed to: David J. Smith, Jr., MD, Plastic and Reconstructive Surgery, University of Michigan Medical Center, 2130 Taubman Center, 1500 E. Medical Center Drive, Ann Arbor, Michigan 48109-0340.
Qurn injuries in the United States number approxiD mately 1.45 million annually, and the majority (1.4 million, or $96 \%$ ) do not require hospitalization [1] Many superficial partial skin-thickness injuries are seen originally in the clinical setting and managed on an outpatient basis. These smaller wounds benefit from rapid wound closure that prevents infection, promotes reepithelialization, and relieves pain. Patients with more extensive burns of this type stand to gain even more from rapid wound closure, as it will reduce morbidity and mortality [2].

Over the years, two approaches for the treatment of burn wounds have evolved. The conservative approach of repetitive wound care involves local dressings, and the more aggressive surgical approach involves removing devitalized tissue and a subsequent program of local wound care. Both approaches have used a variety of techniques including saline compresses, topical antimicrobial agents, biologic dressings, synthetic dressings, and skin substitutes. The physician must have an understanding of the underlying principles involved in wound healing, which allow assessment of the wound and development of appropriate treatment protocols to maximize those principles in favor of the patient [3].

\section{PHYSIOLOGY OF THERMAL INJURY}

An acute thermal injury results in the loss of a physical barrier to infection, and this loss is accompanied by an inflammatory response. The inflammatory response stimulates both local and systemic mediators that direct and modulate wound healing. In extensive injury, these mediators have physiologic and immunologic impact, both at the local site of injury and systemically. While these mediators are designed to initiate and sustain the healing process, the extensive inflammatory response often results in collateral tissue destruction. Heggers and Robson $[4,5]$ have previously shown that such inflammatory mediators as prostaglandins and thromboxanes are damaging to the normal tissue surrounding the burn wound and leave this normal tissue more susceptible to microbial invasion. Till and colleagues [6] and Woolliscroft et al [7] have clearly demonstrated that this inflammatory cascade is selfperpetuating and may result in increased tissue destruction and necrosis rather than wound healing (Figure 1). Mediators, such as the cytokine interleukin-8, are associated with tissue injury, and such local events may influence systemic immune function [8]. Other investigators have also described alterations of local immunity that predispose to burn wound sepsis [9].

\section{THERMAL INJURY AND INFECTION}

Although bacteria have been implicated in the initiation of wound healing $[10,11]$, colonization of tissue 


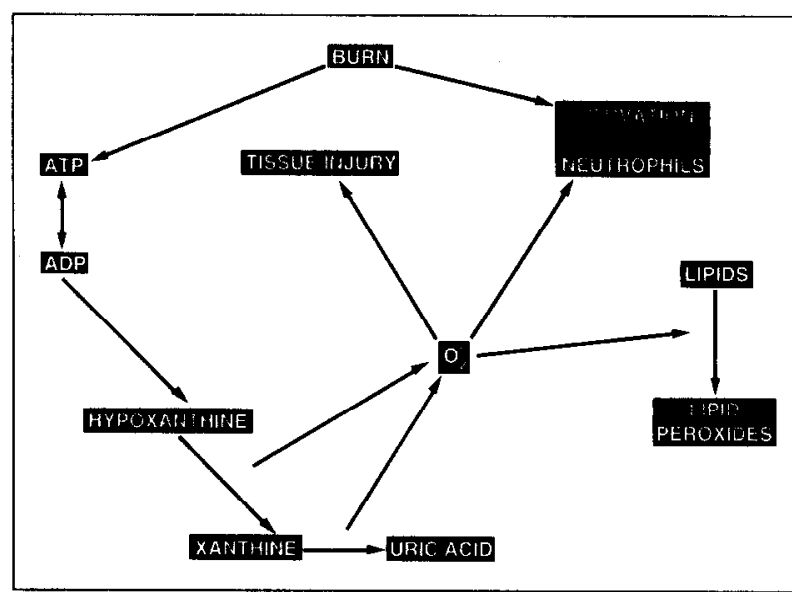

Figure 1. Cyclic model of tissue injury in burned patients. ADP = adenosine diphosphate; ATP = adenosine triphosphate; $\mathrm{O}_{2}=$ oxygen. (Reprinted with permission from [7].)

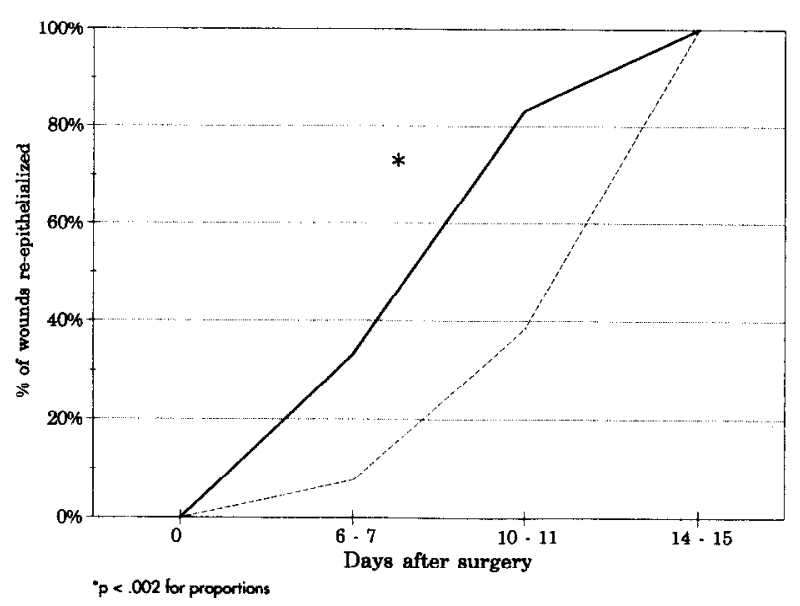

Figure 2. Healing rate of superficial wounds dressed with hydrocolloid dressing $(-)$ or with conventional gauze dressing (---). (Reprinted with permission from [22].)

compromised by inflammation may lead to local invasion and systemic sepsis. In some studies, an inverse relationship between wound healing and bacterial count has been found $[12,13]$. These findings have led to an overall acceptance of the concept that bacteria recovered in high numbers from a wound are not to be tolerated. However, the majority of burn wounds are superficial, partial skin-thickness, and of moderate size. These injuries are limited, and the risk of systemic sepsis is low. In the past, even superficial burn wounds were treated with topical antimicrobial dressings to decrease the risk of infection and subsequent systemic sepsis. In locally infected wounds, antimicrobial dressings, such as silver sulfadiazine, have proved to be valuable [14]. A growing body of evidence, however, suggests that certain topical antimicrobials may have a delaying effect on keratinocyte proliferation, cultured skin, and healing [15-17]. Therefore, the need to reduce bacteria in the wound must take into account the relative risk:benefit ratio of the planned therapy.

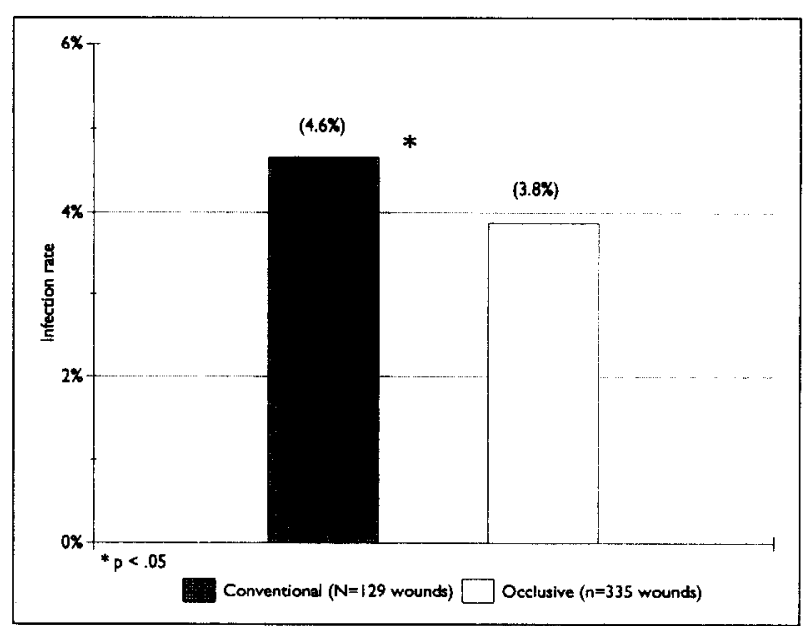

Figure 3. Infection rates for burn wounds dressed conventionally or occlusively. (Adapted with permission from [23].)

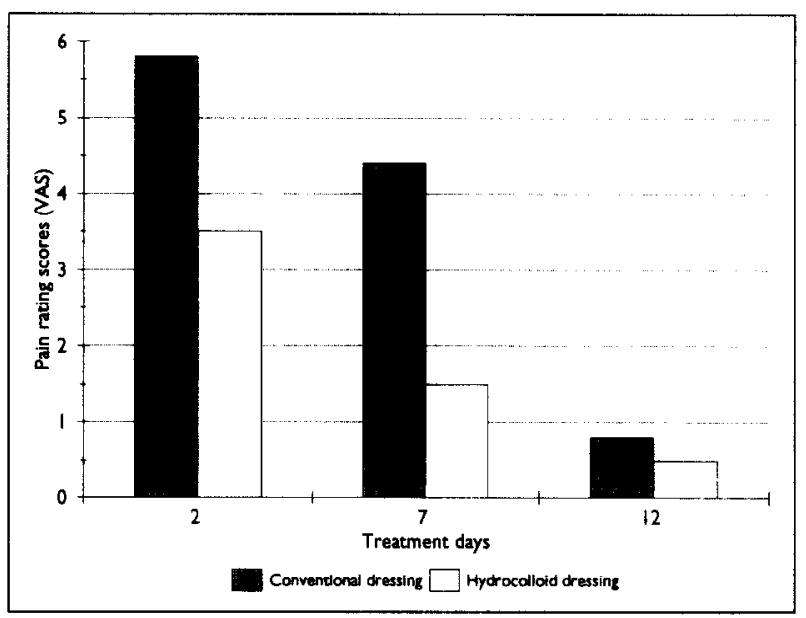

Figure 4. Reported visual analog pain assessment of superficial wounds dressed either with hydrocolloid or conventional dressings. (From [24].)

\section{MANAGEMENT OF NONINFECTED BURN WOUNDS}

In noninfected burn wounds, it is possible to use treatment modalities that do not contain topical antimicrobials. Biologic dressings, such as cadaver allografts, amnion, and xenografts, are effective methods to treat wounds of limited size, but risk of disease transfer, ultimate rejection, and restricted availability of these modalities are potential problems. Shah and colleagues [18] suggested that, by evolutionary selection, the speed of healing has been optimized at the expense of the ultimate quality of the healed skin. These authors suggest that the normal adult wound demonstrates an excessive cytokine response that can be reduced without compromising the speed of healing or acquisition of tensile strength, and with beneficial effects in the final development of scar.

Winter [19] has shown that moist wounds heal faster than desiccated wounds. Previous studies have documented the fact that occlusive dressings are beneficial in speeding the rate and quality of wound healing [20-22], 
in comparison to dressings that result in desiccated wounds (Figure 2). The acute partial skin-thickness burn wound may benefit from treatment with occlusive hydrocolloid dressings. Reports of this treatment plan have suggested that burn wound healing is increased without the subsequent increase in infection (Figure 3) [23]. In limited superficial wounds, restoration of normal skin function and appearance are equally as important as wound closure. The conventional treatment of superficial wounds involves repetitive wound dressings with topical antimicrobials and increased pain for the patient, making this approach to wound care a less desirable alternative. Hydrocolloid dressings used for the treatment of other superficial wounds have been shown to reduce pain significantly when compared with conventional gauze dressings (Figure 4) [24].

In conclusion, superficial burn wounds without necrosis or infection may benefit from moisture retentive hydrocolloid dressings. Colonization or harboring of skin flora organisms over the surface of such wounds does not seem to interfere with normal wound healing. Finally, hydrocolloid treated burn wounds have been shown to have a reduced infection rate when compared to conventionally treated wounds.

\section{REFERENCES}

1. Rice DP, MacKenzie EJ, Jones AS, et al. Cost of injury in the United States-1989. Report to Congress; XXIX.

2. Scott-Connor CE, Meydrech E, Wheeler WE, et al. Quantitation of rate of wound closure and the prediction of death following major burns. Burns 1988; 26: 123.

3. Hunt TK. Basic Principles of Wound Healing. J Trauma 1990; 30: S122.

4. Heggers JP, Robson MC. Evaluation of burn blister fluid. Plast Reconstr Surg 1980; 65: 798-804.

5. Heggers JP, Robson MC. Burns. Prostaglandins and thromboxane. Crit Care Clin 1985; 1: 59-77.

6. Till GO, Guilds LS, Mahrougui M, Friedl HP, Trentz O, Ward PA. Role of xanthine oxidase in thermal injury of skin. Am J Pathol 1989; 135: 195-202

7. Woolliscroft JO, Prasad JK, Thomson PD, et al. Metabolic alterations in burn patients: detection of adenosine triphosphate degradation products and lipid peroxides. Burns 1990; 16: 92-6.

8. Garner WL, Rodriguez JL, Miller C, Smith DJ, Remick DR. Acute skin injury releases neutrophil chemoattractants. Surg Forum 1991; 42: 617-8.

9. Deitch EA, Dobke EM, Baxter CR. Failure of local immunity A potential cause of burn wound sepsis. Arch Surg 1985; 120: $78-84$.

10. Tenorio A, Jindrak K, Weiner $M$, et al. Accelerated healing in infected wounds. Surg Gynecol Obstet 1976; 142: 537-43.

11. Kan Gruber D, Gruber C, Seifter E, et al. Acceleration of wound healing by Staphylococcus aureus. Surg Forum 1981; 32: 76-8.

12. Lookingbill DP, Miller SH, Knowles RC. Bacteriology of chronic leg ulcers. Arch Dermatol 1978; 114: 1765-8.

13. Robson MC, Lea CE, Dalton JB, Heggers JP. Quantitative bacteriology and delayed wound closure. Surg Forum 1986; 19: $501-2$.

14. Taddonio TE, Thomson PD, Smith DJ, Prasad JK. A survey of wound monitoring and topical antimicrobial therapy practices in the treatment of burn injury. J Burn Care Rehabil 1990; 11: 423-7. 15. McCauley RL, Poole $B$, Heggers JP, et al. Differential in vitro toxicity of topical antimicrobial agents to human keratinocytes. Proc Am Burn Assoc 1990; 22: 2.
16. Teepe RGC, Koebrugge EJ, Lowik CWGM, Petit PLC et al Cytotoxic effects of topical antimicrobial and antiseptic agents on human keratinocytes in vitro. J Trauma 1993; 35: 8-19.

17. Boyce ST, Holder IA. Selection of Topical Antimicrobial agents for cultured skin for burns by combined assessment of cellular cytotoxicity and antimicrobial activity. J Plast Reconstr Surg 1993; 92: 493-500.

18. Shah M, Foreman DM, Ferguson MWJ. Control of scarring in adult wounds by neutralizing antibody to transforming growth factor $\beta$. Lancet 1992 ; $i$ : $213-4$

19. Winter GD. Formation of the scab and the rate of epithelial ization of superficial wounds in the skin of the young domestic pig. Nature 1962; 193: 293-4

20. Hermans MHE, Hermans RP. Preliminary report on the use of a new hydrocolloid dressing in the treatment of burns. Burns 1984; 11: 125-9.

21. Hermans MHE. Treatment of burns with occlusive dressing some pathophysiological and quality of life aspects. Burns 1992; 10 S15-8.

22. Smith DJ, Thomson PD, Bolton LL, Hutchinson JJ. Microbiology and healing of the occluded skin-graft donor site. Plast Reconstr Surg 1993; 91: 1094-7.

23. Hutchinson $J J$, McGuckin $M$. Occlusive dressings: a microbiologic and clinical review. Am J Infect Control 1990; 18: 257-68.

24. Hickerson WL, Kealey GP, Smith DJ, Thomson PD. A prospective comparison of a new, synthetic donor site dressing versus Xeroform. J Burn Care Rehabil 1993; (in press).

\section{DISCUSSION}

C. Baxter: I have had good experience treating paticnts with burns on the arm. They are less painful, one does not have to do a lot of dressing changes, they are easier to take care of, and the patients are happier. Even with metal burns, which take longer to heal, the patient is still happy while the wound is healing. I do not see anything wrong with it.

D. Smith: My only comment to that would be that depth is difficult to assess at the time you see the patient. I do remember a study by Marty Robson, where he covered burns with Xeroform and wrapped them without changing them for 10 days. They healed faster than if they were changed regularly. This was very good. The only problem is that it is painful, and they dry out under those dressings.

M. Kerstein: In our study of small burns, they used silver sulfadiazine because of its ease of application and convenience. Of course, it is not convenient in terms of what clothes one wears with it and whether these patients can go to work and function in society.

D. Smith: Patients also expect burns to get infected, so an education process is needed. They need to know that the exudate and odor are not an infection before they see it.

C. Baxter: They use silver sulfadiazine frequently on outpatients. The physician never sends a burn out open because it will get infected. It should be covered up with something that makes it soft, pliable, and can be moved without pain. We studied matched burns treated with and without topical antimicrobials 15 years ago and found equal infection rates. 